\title{
АКТУАЛЬНЫЕ КОНЦЕПЦИИ ДОСТИЖЕНИЯ ПОЛИТИЧЕСКОГО БЛАГОПОЛУЧИЯ: ТРАНСФОРМАЦИЯ КОНЦЕПТА «МЯГКОЙ СИЛЫ» В СОВРЕМЕННОМ НАУЧНОМ ДИСКУРСЕ
}

\author{
Смирнов Василий Андреевич, \\ novtransa2010@yandex.ru
}

Новгородский государственный университет имени Ярослава Мудрого, Россия, 173003, г. Великий Новгород, ул. Большая Санкт-Петербургская, 41

\begin{abstract}
Смирнов Василий Андреевич, кандидат философских наук, доцент кафедры теории, истории и
\end{abstract} философии культуры Новгородского государственного университета имени Ярослава Мудрого.

\begin{abstract}
Актуальность исследования предопределена той научной популярностью, которую в последнее время приобрела концепция «мягкой силы», являющаяся наиболее эффективным способом властвования в современную эпоху. Цель работы - рассмотрение концепта «мягкой силы» через призму таких теоретических направлений, как конструктивизм, структурализм и культурологическая теория. Методы: аксиологический подход, дающий возможность ценностного измерения исследуемых социокультурных явлений, и конструктивистский подход, рассматривающий «мягкую силу» как каркас культурного производства определенных символических схем, конструирующих социальную реальность. Выводы: во-первых, стратегии «мягкой силы» дают возможность без видимого применения прямого и жесткого давления воздействовать на ментальные структуры массового сознания. Во-вторых, политика на современном этапе представляет собой арену конкурирующих между собой символических и культурных универсумов, стремящихся навязать различным аудиториям собственные знаковые «реальности», и именно "мягкой силе» как механизму аппликации этих «культурных кодов» принадлежит ведущая роль в политических практиках. Результатом является соотнесение теории «гегемонии» Грамши с концепцией «мягкой силы». Различие заключается в том, что "мягкая сила» - это, скорее, инструмент внешнеполитического воздействия, трансляции и продвижения собственных культурных кодов «вовне» с помощью разных способов (публичная дипломатия, телевещание, Интернет и т. д.), тогда как «гегемония» - механизм «внутреннего» сохранения власти правящей буржуазией. На основании всего вышеизложенного можно заключить, что «мягкая сила» останется важнейшим инструментом аппликации власти в современном социокультурном пространстве.
\end{abstract}

Ключевые слова: Мягкая сила власти, конструктивизм, культурная политика, матрицы убеждений, символические универсумы, культурная и политическая гегемония, рычаги социокультурного влияния.

В современном мире одним из ведущих политических и социокультурных концептов, повсеместная реализация которого, по мнению его авторов и адептов, должна обернуться резким всплеском благополучия во всем цивилизованном мире, является «мягкая сила». Понятие «мягкой силы» было впервые введено в научный дискурс профессором Гарвардского университета Дж. Наем. Как считает ученый, сила государства фундируется не только материальными ресурсами в виде военной и экономической мощи (так называемая «hardpower»), но во многом зависит от использования «мягких» инструментов в политике. В реализации принципов «мягкой силы» важно оказание влияния на изменение приоритетов чужих стран и народов таким образом, чтобы «они 
захотели того, чего хотите вы, и вам не пришлось бы заставлять их изменить свое поведение» [1, с. 57].

Феномен «мягкой силы» может быть понят более полно, если взглянуть на него через призму теории конструктивизма, социальную теорию Бурдье и культурологическое направление Клиффорда Гирца. Кроме того, можно найти очень много общих черт между концепцией мягкой мощи Дж. Ная и теорией гегемонии Антонио Грамши.

По мнению конструктивистов, социальная реальность - это искусственно созданная матрица убеждений, с помощью которой люди интерпретируют окружающий их мир. При этом мировая политика с точки зрения аппликации «мягкой силы» представляет собой конкуренцию этих матриц, когда альтернативные друг другу символические модели стараются не только формально завоевать «место под солнцем», но и в исключительных случаях пытаются так или иначе стереть враждебные им социокультурные структуры. Согласно К. Гирцу, все символические системы фундируются культурными образами. Символы являются отражением в нашем сознании объектов внешней реальности, тогда как культура снабжает человека определенными символами, помогающими ему ориентироваться в окружающем мире. Внутри себя человек имеет слишком мало шаблонов для организации культурного поведения, поэтому оно должно дополнительно направляться внешними источниками. Конкретные модели поведения человека регулируются не столько генетическими программами, сколько культурными шаблонами [2]. При этом разные символические дискурсы не только мирно уживаются между собой, но и пытаются активно вытеснить «конкурентов».

По мнению Е.П. Пановой, большую роль в данном «символическом соперничестве» играют вербальные «войны», т. к. люди в целом воспринимают реальность лишь через «очки» определенных лингвистических систем [3, с. 92]. П. Бурдье в своих исследованиях социальных структур особое внимание уделяет процессам номинации, полагая, что политическая власть обладает уникальной возможностью «творить» социальный порядок. «Во многих архаических обществах власть облекалась в форму называть и давать жизнь вещам при помощи процесса номинации. Особенно ярко это проявлялось во времена кризисов. Так, способность творить символы приносила некоторым поэтам древности видные посты в аппарате управления (посты военачальников или послов)» $[4$, с. 462$]$. Он также непосредственно соединяет власть и слово: «Самая сильная власть является таковой до тех пор, пока она имеет возможность осуществлять в полной мере символическое насилие. Можно даже сказать, что данное насилие будет тем более эффективным, чем сильнее его проявления будут носить скрытый характер. При этом часто политик старается заручиться неким высшим одобрением» на свои действия, заявляя: «Бог с нами». Эквивалентом этого утверждения в наши дни стала фраза: «Общественное мнение с нами» [4, с. 69.].

Власть слова проявляется, в том числе, в возможности воздействовать на других членов группы, применяя так называемое «символическое насилие». Символический универсум интегрирует самые разные значения, существующие в повседневной жизни. Он также упорядочивает историю, иногда принудительно связывая коллективные события в единое целое, включающее прошлое, настоящее и будущее. По отношению к прошлому создается искусственная «память», объединяющая всех, кто социализирован в данной общности. Символические универсумы осуществляют исчерпывающую интеграцию всех разрозненных институциональных процессов, тогда как отдельные социальные институты и роли легитимируются благодаря их включению во всеобъемлющий смысловой мир. Например, политический порядок легитимируется благодаря его соотнесению с космическим порядком власти и справедливости, а политические роли 
легитимируются в качестве репрезентаций этих космических принципов [5]. Символический универсум не только легитимируется, но и видоизменяется с помощью концептуальных механизмов, создаваемых для того, чтобы отрицать вызов, брошенный девиантными (т. е. отклоняющимися в своем мировоззрении от установленных образцов символического универсума) группами.

В качестве последнего по времени и наиболее яркого примера навязывания аудитории своей картины мира через лингвистические (символические) структуры можно привести уже порядком поднадоевшую всему цивилизованному миру фразу «борьба с терроризмом». Ведь именно ее Соединенные Штаты Америки повсеместно использовали, для того чтобы заручиться формальной легитимизирующей поддержкой остальных стран во время планируемых военных операций против Афганистана и Ирака. Такое словосочетание ясно маркировало «плохие силы» (слово «терроризм» во всех языках однозначно имеет негативную коннотацию) и отделяло от них «хорошую» страну в лице Соединенных Штатов, которая ведет непримиримую борьбу с этой современной разновидностью «мирового зла». На этом основании можно сделать вывод, что первоначальный тезис о непринудительном характере «мягкой силы» является не вполне правомерным и исчерпывающим. Поскольку современная политика представляет собой арену конкурирующих между собой символических дискурсов, стремящихся навязать различным аудиториям собственные вербальные «фильтры» с помощью целого спектра сил и средств.

Можно считать, что теория «мягкой силы» Дж. Ная во многих чертах заимствует положения итальянского мыслителя А. Грамши о гегемонии. По мнению автора, механизм власти включает в себя не только принуждение, но и убеждение. Любое государство, безотносительно того, какой класс в данный момент является доминирующим, опирается на два фундаментальных столпа - силу и согласие. Если в обществе превалируют методы ненасильственного властвования, то такое положение дел может быть охарактеризовано как гегемония. При этом последняя не является неким застывшим состоянием, а представляет собой тонкий и весьма лабильный процесс. Гегемония - это не просто пассивное согласие граждан, это активное желание того же, что нужно и самому правящему классу [6]. Гегемония, по мнению А. Грамши, выступает в качестве инструмента культурного господства буржуазии над остальным обществом. Само собой, буржуазия не только контролирует экономику и государственный аппарат, она также является и культурно доминирующей силой. Иными словами, сила буржуазии заключается не только в применении «жесткой» силы, но также и в использовании «мягкой», в сочетании материальных факторов господства с идеологическими.

По Грамши, и установление, и подрыв гегемонии - «молекулярный» процесс. Он протекает не столько как столкновение классовых сил, но как невидимое изменение мнений и настроений в сознании каждого человека. Гегемония опирается на «культурное ядро» общества, которое включает в себя совокупность представлений о мире и человеке, о добре и зле, прекрасном и отвратительном, множество символов и образов, традиций и предрассудков, знаний и опыта многих веков. Пока это ядро стабильно, в обществе имеется «устойчивая коллективная воля», направленная на сохранение существующего порядка. Подрыв этого «культурного ядра» и разрушение этой коллективной воли - условие революции. Создание этого условия - «молекулярная» агрессия против культурного ядра. Это не изречение некой истины, которая совершила бы переворот в сознании, какое-то озарение, это то огромное количество книг, брошюр, журнальных и газетных статей, разговоров и споров, которые без конца повторяются и в своей гигантской совокупности образуют то длительное усилие, из которого рождается 
коллективная воля, которая необходима, чтобы получилось координированное и одновременное действие [7].

Однако, находя общие черты между концепциями Грамши и Ная, можно прийти к следующему выводу: если гегемония Грамши - это «внутренняя» власть буржуазии над «своими» классами, то «мягкая сила» Ная - это стремление распространить собственные культурные и социальные ценности «вовне», на другие страны. Однако и в этом случае «мягкость» все равно будет означать несиловое воздействие.

Отличие «мягкой» силы от «жесткой» заключается не в непринудительной природе первой, а исключительно в формных основаниях этих двух инструментов навязывания своей воли. Если «жесткая» сила оперирует преимущественно военными и экономическими ресурсами, то «мягкая», напротив, воздействует не на «тело» потенциального объекта управления, а на его культурно-символические образы. Так, под влиянием критики конструктивистов, Дж. Най уже в середине 2000-х несколько изменил свои первоначальные взгляды. Он писал: «В использовании мягкой силы могут прослеживаться элементы угроз и манипулирования. Тем не менее она оставляет большую свободу выбора, чем физическая сила» [8, с. 142]. Для того чтобы подорвать «культурное ядро» противника и заменить его своим «культурным ядром», надо воздействовать на обыденное сознание, повседневные, «маленькие» мысли среднего человека. И самый эффективный способ воздействия - неустанное повторение одних и тех же утверждений, чтобы к ним привыкли и стали принимать не разумом, а на веру. «Массы как таковые не могут усваивать философию иначе, как веру» [6, с. 38].

Второй немаловажный вопрос, который касается дефиниции пределов использования «мягкой власти», связан с выявлением наиболее эффективных инструментов её аппликации. В современных условиях, в эпоху информационного общества, значительно изменяется природа политической власти. Она перемещается в виртуальное пространство - в мир образов, имиджей и символов [9]. Как пишет Е.П. Панова, «в таком случае со всей очевидностью встает вопрос о том, можно ли создать условия для использования «мягкой власти», при которых она имела бы более длительный эффект, и какие ресурсы, доступные государствам, могли бы это обеспечить. Как представляется, такие возможности у современного государства имеются, и такие страны, как, например, США, на протяжении многих десятилетий их успешно используют» [3, с. 93].

К наиболее эффективным инструментам исследователь относит образование, развитие социально-гуманитарного знания, а также активное использование так называемой «публичной дипломатии». И если до недавнего времени основным средством идеологического воздействия на целевые страны было иновещание с помощью телеканалов («Russia Today», «CCCTV», «Al-Jazeera»), то теперь все большую роль начинают играть интернет-технологии или так называемая «публичная дипломатия 2.0». Этот термин впервые был использован заместителем госсекретаря США Дж. Глассманом в 2008 г. для обозначения нового подхода в рамках публичной дипломатии, предполагающего использование социальных сетей, блогов, игровых мобильных приложений в осуществлении внешнеполитических целей США [10]. Как справедливо замечает А.Н. Марчуков, «публичная дипломатия 2.0» представляет собой весьма перспективное направление в рамках публичной дипломатии, значение которого во внешнеполитической деятельности государств со временем будет только усиливаться.

Развитие информационно-коммуникативных технологий и растущая популярность в мире социальных медиа актуализируют необходимость использования технологий Web 2.0 в дипломатической практике. Однако подобная деятельность не должна ограничиваться лишь наличием у внешнеполитических ведомств аккаунтов в социаль- 
ных сетях и микроблогах; каждому государству необходимо иметь собственную стратегию развития «публичной дипломатии 2.0». Следует осознавать, что воздействовать на формирование общественного мнения за рубежом с помощью технологий Web 2.0 достаточно сложно, но тем не менее данный способ может быть весьма продуктивным в вопросе создания положительного образа государства за границей [11]. По мнению О.Ф. Русаковой, другим проверенным инструментом мягкой гегемонии может являться массовое тиражирование продуктов поп-культуры той или иной страны [12].

В 2008 г. Дж. Най в очередной раз скорректировал источники структуры «мягкой силы». Им были обозначены три основные составляющие этого вида политической мощи: внешняя политика, политические ценности (если внутренняя и внешняя политика государства коррелирует с ними), культура (куда входит и «массовая культура») [13]. Касаясь вопроса эффективности каналов использования «мягкой силы» многие исследователи обращают внимание на то, что «с одной стороны, рост мировой напряженности, тотальная турбулентность предполагают осторожные коммуникации по проверенным тропам (традиционная дипломатия). С другой стороны, очевидно, что без открытых информационных платформ дипломатические каналы воздействия «мягкой мощи» практически обесцениваются. Цели, действия и результаты в сфере официальной дипломатии должны иметь PR-поддержку, в том числе через публичную дипломатию и т. н. «третий» (некоммерческий) сектор. Традиционную и публичную дипломатии (коммуникативные субструктуры которых существуют в медиапространстве) необходимо выделить как наиболее эффективные каналы распространения «мягкой мощи». Но они не самодостаточны: действия должны сопровождаться интернет-поддержкой, в частности через профильные виртуальные сети» [14, с. 148-149].

За последние десятилетия различные государства по-разному пытались реализовать потенциал «мягкой силы» во внешней политике, что позволяет говорить о существовании нескольких различных стратегий ее использования. Наряду с традиционной (американской) принято выделять европейскую, советскую, японскую, российскую и китайскую стратегии использования «мягкой силы». Такое деление обусловлено национально-историческими особенностями внешнеполитических установок государств, различающихся содержанием имеющихся ресурсов и проводимых мероприятий [15]. Названные стратегии можно условно разделить на «старые» (традиционные) и «новые» (современные). К числу традиционных стратегий «мягкой силы» могут быть отнесены американская, китайская, японская и советская стратегии, поскольку в этих странах раньше, чем в других, «мягкая сила» стала использоваться в качестве целенаправленного инструмента внешней политики. К современным стратегиям относятся европейская (ЕС), российская и стратегии новых независимых государств (например, стран СНГ), т. е. стратегии вновь образованных государств и интеграционных объединений. Необходимо отметить, что отличительной чертой второй группы стратегий является историческая преемственность накопленного в прежние времена потенциала «мягкой силы» [15, с. 32]. А.М. Бобыло отмечает, что основным инструментом американской «мягкой силы» является публичная дипломатия (public diplomacy). Центральная роль в ее осуществлении принадлежит информационному воздействию и контролю над информационными потоками. Китай и Европа, в большей степени, используют культурные инструменты влияния.

В заключении хотелось бы отметить, что культура выступает важнейшей основой распространения «мягкой силы» [16], поскольку именно культурная идентичность и обеспечивает формирование так часто упоминаемой привлекательности [1]. Например, так называемые «новые» социокультурные ценности, пропагандируемые КНР, не толь- 
ко сплачивают ханьцевьпо всему миру [17], но и транслируют ценности китайской цивилизации на остальные страны, которые начинают относиться к Пекину с благожелательностью. В целом Китай использует два мощных наступательных инструмента для продвижения своего имиджа за рубежом. Во-первых, это образовательные программы, позволяющие активно привлекать в китайские университеты студентов со всего мира. Образование в современном мире - это один из самых оптимальных и интенсивных способов приобщения человека к ценностям той или иной культуры [18]. Во-вторых, это позиционирование себя как культурно-цивилизационной силы, способной стать альтернативой Западной цивилизации [19]. Можно с полным основанием утверждать, что после краха СССР, предлагавшего миру свою систему ценностей, данная ниша вполне может быть занята Китаем. Тем более Пекин делает ставку на достаточно привлекательную для многих стран «политику невмешательства» во внутренние дела своих соседей, «что в корне отличает китайскую дипломатию от американской и способствует сближению с традиционными стратегическими партнерами США (Таиландом и Филиппинами), руководство которых стало объектом критики американской администрации за нарушение прав человека» [20, с. 31].

Таким образом, мы можем сделать следующие важные выводы. Дискурс «мягкой силы» дает возможность без видимого применения прямого и жесткого давления использовать воздействие на ментальные структуры массового сознания. «Мягкая сила» опирается на искусственно сконструированные матрицы убеждений, с помощью которых люди интерпретируют окружающий их мир. Современная политика представляет собой арену конкурирующих между собой символических и культурных универсумов, стремящихся навязать различным аудиториям собственные знаковые «реальности». В отличие от «гегемонии» Грамши, «мягкая сила» - это в первую очередь не инструмент доминирования буржуазии, а государственный механизм трансляции и продвижения собственных культурных кодов «вовне» с помощью разных инструментов (публичная дипломатия, телевещание, Интернет и т. д.). В последние года различные государства по-разному пытались реализовать потенциал «мягкой силы» в политике, что позволяет говорить о существовании нескольких различных политических и социокультурных стратегий ее использования. На основании всего вышеизложенного можно заключить, что «мягкая сила» останется важнейшим инструментом аппликации власти в современном социокультурном пространстве.

\section{Список литературы}

1. Федотова Н.Н. Анализ культурных ресурсов: мягкая мощь и идентичность // Философия и современность. - 2016. - № 4. - С. 55-69.

2. Гирц К. Интерпретация культур - М.: Россмэн, 2004. - 560 с.

3. Панова Е.П. Сила привлекательности: использование «мягкой власти» в мировой политике // Вестник МГИМО. - 2010. - С. 91-97. URL: https://cyberleninka.ru/article/n/sila-privlekatelnosti-ispolzovaniemyagkoy-vlasti-v-mirovoy-politike (дата обращения 12.03.2019).

4. Бурдье П. Социология политики - M.: Socio-Logos, 1993. - 336 с.

5. Бергер П., Лукман Т. Социальное конструирование реальности. Трактат по социологии знания. - М.: Медиум, 1995. - 322 с.

6. Грамши А. Тюремные тетради. Часть первая. - М.: Издательство политической литературы, 1991. $560 \mathrm{c}$.

7. Кара-Мурза С.Г. Манипуляция сознанием. - М.: ЭКСМО-Пресс, 2001. - 832 с.

8. Nye J. The Powers to Lead. - Oxford: Oxford University Press, 2010. - 248 p.

9. Голобородько А.Ю. Имидж страны в мировом информационном пространстве: к вопросу о «мягкой силе» влияния // Вестник Поволжской академии государственной службы. - 2013. - № 2 (35). C. $38-43$. 
10. Glassman J.K. Public Diplomacy 2.0: a new approach to global engagement. URL: http://20012009.state.gov/r/us/2008/112605.htm (дата обращения 12.03.2019).

11. Марчуков А.Н. «Публичная дипломатия 2.0» как инструмент внешнеполитической деятельности // Вестник Волгоградского государственного университета. Серия 4 «История. Регионоведение. Международные отношения». - 2014. - № 4 (28). - С. 104-113.

12. Русакова О.Ф. Дискурс soft-power во внешней политике // Вестник ЮУрГУ. - № 32 (291). - 2012. C. $118-121$.

13. Nye J. Public Diplomacy and Soft Power // The Annals of the American Science Academy of Political and Social. - 2008. - V. 616. - Iss. 1. - P. 94-109. URL: https://journals.sagepub.com/doi/pdf/10.1177/ 0002716207311699 (дата обращения 12.03.2019).

14. Изотов В.С. «Мягкая мощь»: обновленный теоретический концепт и российская модель для сборки // Вестник Российского университета дружбы народов. Серия «Политология». - 2011. - № 4. - С. 146-155.

15. Бобыло А.М. Национальные стратегии «мягкой силы» во внешней политике США, КНР и Российской Федерации: основные направления и особенности регионального развития // Гуманитарные исследования в Восточной Сибири и на Дальнем Востоке. - 2015. - № 3. - С. 31-39.

16. Макаревич Э.Ф. Привлекательность мягкой силы и способы ее измерения // PolitBook. - 2017. Т. $1 .-$ C. $30-48$.

17. Мефодьева С.А. Практики китайских и российских СМИ в распространении «мягкой силы государств» (на примере их освещения в CCTV NEWS и RT) // Власть. - 2019. - № 1. - С. 196-200.

18. Заугаров В.В. Международный опыт использования высшего образования как ресурса «мягкой силы государств» // Вестник финансового университета. Гуманитарные науки. - 2018. - № 6. - С. 19-23.

19. Wilson J. L. Soft power: a comparison of discourse and practice in Russia and China // Europe and Asia Studies. - 2015. - V. 67. - № 8. - P. 1171-1202. URL: https://doi.org/10.1080/09668136.2015.1078108 (дата обращения 12.03.2019).

20. Рогожина Н.Г. «Мягкая сила» в политике Китая в странах Юго-Восточной Азии // Юго-Восточная Азия: Актуальные проблемы развития. - 2017. - Вып. XXXIV. - № 34. - C. 24-33.

Поступила 25.03.2019 г. 
UDC 364.658:323.21:81’42

\title{
CURRENT CONCEPTS OF ACHIEVING POLITICAL WELL-BEING: TRANSFORMATION OF THE CONCEPT OF «SOFT POWER» IN MODERN SCIENTIFIC DISCOURSE
}

\author{
Vasily A. Smirnov, \\ novtransa2010@yandex.ru \\ Yaroslav the Wise Novgorod State University, \\ 41, Bolshaya Sankt-Peterburgskaya street, Veliky Novgorod, 173003, Russia
}

Vasily A. Smirnov, Cand. Sc., associate professor, Yaroslav the Wise Novgorod State University.

The relevance of the research is predetermined by the scientific popularity that the concept of "soft power» has recently acquired. The aim of this work is to examine the concept of «soft power» through the prism of such theoretical approaches as constructivism, structuralism and cultural theory. Methods: the axiological approach that allows evaluating socio-cultural phenomena, the constructivist approach that analyses «soft power» as a framework for cultural production of certain symbolic schemes that construct social reality. The article draws the following important conclusions: firstly, soft power strategies make it possible to use influence on the mental structures of mass consciousness without the visible use of direct and hard pressure. Secondly, politics at the present stage is an arena of competing symbolic and cultural universes that seek to impose their own iconic «realities» on different audiences. «Soft power» as a mechanism for applying these «cultural codes» plays a leading role in the political practices. The result of the research is the Gramsci's theory of "hegemony» compared with the concept of «soft power». The difference between them is that "soft power» is rather a tool for foreign policy influence, whereas «hegemony» is a mechanism for «internal» preservation of power by a ruling class. In the end we can conclude that «soft power» will remain the most important tool for applying power in the modern socio-cultural space.

Key words: Soft power, constructivism, cultural policies, cultural matrix of beliefs, symbolic universe, cultural and political hegemony, levers of social and cultural influence.

\section{References}

1. Fedotova N.N. Analysis of cultural resources: soft power and identity. Filosofiya i sovremennost, 2016, no. 4, pp. 55-69. In Rus.

2. Girts C. Interpretatsiya kultur [The interpretation of cultures]. Moscow, Rossmen Publ., 2004. 560 p.

3. Panova E.P. The power of attractiveness: the use of «soft power» in world politics. Vestnik MGIMO, 2010, pp. 91-97. In Rus. Available at: https://cyberleninka.ru/article/n/sila-privlekatelnosti-ispolzovaniemyagkoy-vlasti-v-mirovoy-politike (accessed 12 March 2019).

4. Bourdieu P. Sotsiologiya politiki [Sociology of politics]. Moscow, Socio-Logos Publ., 1993. 336 p.

5. Berger P., Lukman T. Sotsialnoe konstruirovanie realnosti. Traktat po sotsiologii znaniya [Social construction of reality. A treatise on the sociology of knowledge]. Moscow, Medium Publ., 1995. 322 p.

6. Gramsci A. Tyuremnye tetradi. Chast pervaya [Prison notebooks. Part one]. Moscow, Izdatelstvo politicheskoy literatury Publ., 1991. 560 p.

7. Kara-Murza S.G. Manipulyatsiya soznaniem [Consciousness manipulation]. Moscow, EKSMO-Press Publ., 2001. $832 \mathrm{p}$.

8. Nye J. The Powers to lead. Oxford. Oxford University Press, 2010. 248 p.

9. Goloborodko A.Yu. Imidzh strany v mirovom informatsionnom prostranstve: $\mathrm{k}$ voprosy o «myagkoy sile» vliyaniya [Image of the country in the world information space: on the issue of «soft power» of influence]. Vestnik Povolzhskoy akademii gosudarstvennoy sluzhby, 2013, no. 2 (35), pp. 38-43.

10. Glassman J.K. Public Diplomacy 2.0: a new approach to global engagement. Available at: http://20012009.state.gov/r/us/2008/112605.htm (accessed: 12 March 2019). 
11. Marchukov A.N. «Public diplomacy 2.0» as an instrument of foreign policy. Vestnik Volgogradskogo gosudarstvennogo universiteta. Seriya 4 «Istoriya. Regionovedenie. Mezhdunarodnye otnosheniya», 2014, no. 4 (28), pp. 104-113. In Rus.

12. Rusakova O.F. Diskurs soft-power vo vneshney politike [Discourse soft-power in foreign policy]. Vestnik YurGU, 2012, no. 32 (291), pp. 118-121.

13. Nye J. Public Diplomacy and Soft Power. The Annals of the American Science Academy of Political and Social, 2008, vol. 616, Iss. 1, pp. 94-109. Available at: https://journals.sagepub.com/doi/pdf/10.1177/ 0002716207311699 (accessed 12 March 2019).

14. Izotov V.S. «Myagkaya moshch»: obnovlenny teoreticheskiy kontsept i rossiyskaya model dlya sborki [«Soft power»: updated theoretical concept and Russian model for Assembly]. Vestnik Rossiiskogo universiteta druzhby narodov. Seriya «Politologiya», 2011, no. 4, pp. 146-155.

15. Bobylo A.M. Natsionalnye strategii «myagkoy sily» vo vneshney politike SShA, KNR i Rossiiskoy Federatsii: osnovnye napravleniya i osobennosti regionalnogo razvitiya [National strategies of «soft power» in the foreign policy of the USA, China and the Russian Federation: the main directions and features of regional development]. Gumanitarnye issledovaniya v Vostochnoy Sibiri i na Dalnem Vostoke, 2015, no. 3, pp. 31-39.

16. Makarevich E.F. Privlekatelnost myagkoy sily i sposoby ee izmereniya [The appeal of soft power and how it will be measured]. PolitBook, 2017, no. 1, pp. 30-48.

17. Mefodeva S.A. Praktiki kitayskikh i rossiyskikh SMI v rasprostranenii «myagkoy sily gosudarstv» (na primere ikh osveshcheniya v CCTV NEWS i RT) [Practices of Chinese and Russian media in the spread of «soft power of States» (CCTV CCTV News RT RT)]. Vlast, 2019, no. 1, pp. 196-200.

18. Zaugarov V.V. Mezhdunarodny opyt ispolzovaniya vysshego obrazovaniya kak resursa «myagkoy sily gosudarstv» [International experience of using higher education as a resource of «soft power of States»]. Vestnik finansovogo universiteta. Gumanitarnye nauki, 2018, no. 6, pp. 19-23.

19. Wilson J. L. Soft power: a comparison of discourse and practice in Russia and China. Europe and Asia Studies, 2015, vol. 67, no. 8, pp. 1171-1202. Available at: https://doi.org/10.1080/09668136.2015.1078108 (accessed 12 March 2019).

20. Rogozhina N.D. «Myagkaya sila» v politike Kitaya v strankh Yugo-Vostochnoy Azii [«Soft power» in China's policy in South-East Asia]. Yugo-Vostochnaya Aziya: Aktualnye problemy razvitiya, 2017, Iss. XXXIV, no. 34, pp. 24-33.

Received: 12 July 2019. 